\title{
Uma Estratégia Exponencial para Redução do Consumo Energético em Redes de Sensores sem Fio
}

\author{
Marcelo O. Marques, Luciano A. F. Santos e Ivanil S. Bonatti
}

\begin{abstract}
Resumo - Uma estratégia de redução do consumo de energia para redes de sensores sem fio é proposta neste trabalho. A estratégia é baseada na alteração do tempo de dormência dos nós sensores em função do nível de atividade do ambiente, de forma a melhorar a relação entre o consumo de energia e o atraso de transferência de pacotes. O aumento ou a diminuição exponencial do tempo de dormência considera não só a freqüência de detecção de novos eventos, mas também o nível de atividade dos nós sensores encaminhando os dados coletados por outros nós. Os resultados das simulações de Monte Carlo mostram que a estratégia proposta diminuiu o consumo de energia da rede sem afetar significativamente o atraso médio de transferência de pacotes na rede, quando comparada com uma estratégia publicada recentemente.
\end{abstract}

Palavras-Chave-Análise e desempenho de redes; Protocolos de comunicação; Redes de sensores.

Abstract-Energy saving strategies to wireless sensor networks changing the sleeping time of sensor nodes as function of activity level of the sensing field, in order to improve the trade-off between the average network energy consumption and the average data delivery delay is presented in this paper. The exponential increase or decrease of sleeping time considers the event detection frequency in the sensing field as well as the level of activity of sensor forwarding sensing data of the others sensor nodes. These strategies have been simulated and the average data delivery delay was compared with the one produced by another strategy recently reported. The simulation results show that the proposed strategy reduces the energy consumption of the sensor nodes with small degradation of the data delivery delay.

\section{INTRODUÇÃO}

Uma rede de sensores sem fio consiste de um grande número de sensores distribuídos geograficamente sobre a área de interesse. Os nós sensores são encarregados do sensoriamento, de processar e encaminhar os seus dados e, também, encaminhar os dados provenientes de nós sensores vizinhos. A rede de sensores auto-organiza-se como uma rede ad hoc para que as informações obtidas pelos sensores sejam encaminhadas através de comunicação multihop para o sink node [1] e [2].

Aplicações típicas para redes de sensores envolvem monitoramento ambiental, aplicações militares e rastreamento.

Marcelo O. Marques, Instituto Nacional de Telecomunicações, INATEL, Santa Rita do Sapucaí, MG, Brasil, e-mail: marcelo@inatel.br.

Luciano A. F. Santos e Ivanil S. Bonatti, Departamento de Telemática, FEEC, Unicamp, Campinas, SP, Brasil, e-mails: \{luciano, ivanil\}@dt.fee.unicamp.br.
Os nós sensores dispõem, em geral, de fontes de energia limitada, tornando-se o consumo de energia uma restrição para o desempenho da rede. Por essa razão, maximizar o tempo de vida do nó e da rede é um dos objetivos principais no desenvolvimento das redes de sensores sem fio [3].

Várias estratégias para redução do consumo de energia dos nós sensores, sem degradar significativamente o desempenho da rede, têm sido propostas, nas quais destacam-se duas ênfases: a formação de agregados locais de nós vizinhos com escolha de um deles para transmitir os pacotes para o nó sink; e a caracterização, baseada em protocolos da camada MAC (Medium Access Control), dos sensores em dois estados operacionais: ativo e dormente. O estado dormente é caracterizado por baixo consumo de energia, pois parte dos circuitos do sensor é desligada. O nó sensor dormente não participa da dinâmica da rede e a topologia da rede muda conforme os nós entram ou saem do estado dormente afetando a operação e o desempenho da rede. Manter o sensor com ciclos longos de atividade pode reduzir o tempo de vida não só do nó sensor, mas também da rede. Vários trabalhos na literatura propõem diferentes estratégias para definir o estado dormente ou ativo dos nós sensores na rede. Hsin e Liu [4] investigaram o uso de sensores redundantes para garantir o desempenho da rede em função do ciclo ativo-dormência dos nós; e compararam um mecanismo de dormência coordenada com o de dormência aleatória. Ye et al. [5] propuseram que os nós dormentes escutem as transmissões para seus vizinhos, e acordem por um breve período de tempo no final da transmissão para serem incluídos como possíveis nexthops. Dam e Langendoen [6] propuseram diminuir o tempo de escuta transmitindo todas as mensagens em rajadas. Lin et al. [7] propuseram que os nós compartilhem seus valores de atraso de transferência de pacotes para alterar a duração do ciclo ativo-dormência de cada nó sensor. Singh e Raghavendra [8] fizeram com que os nós vizinhos que escutassem uma transmissão passassem para o estado dormente, pois estariam impossibilitados de transmitir ou receber pacotes. Chiasserini e Garetto [9] propuseram um modelo analítico, validado por simulação, para análise de desempenho da rede em função do ciclo ativo-dormência dos nós sensores.

No presente trabalho é apresentado uma estratégia para redução do consumo energético dos nós sensores, na qual a probabilidade de transição de dormente para ativo é função do nível de atividade do ambiente monitorado. O tempo de dormência dos nós sensores é geometricamente 
aumentado ou reduzido, de forma a gradualmente encontrar um ciclo de atividade aceitável, permitindo um melhor e mais eficiente uso das fontes de energia e aumentando, por conseqüência, o tempo de vida da rede. A estratégia apresentada por [9] é semelhante ao modelo apresentado neste trabalho. Todavia, em [9] o tempo de dormência dos nós sensores é independente da atividade da área monitorada. Diferentemente, esta proposta considera não só a freqüência de detecção de novos eventos, mas também o nível de atividade dos nós sensores encaminhando os pacotes de dados coletados por outros nós.

A apresentação restante do trabalho é organizada da seguinte forma: O modelo de rede para simulação é descrito na Seção II. Na Seção III, os principais parâmetros da simulação são apresentados e os resultados comparados com outra estratégia de redução do consumo de energia recentemente publicada em [9] e, finalmente, a Seção IV apresenta as principais conclusões do trabalho.

\section{Modelo DE REDE}

O modelo de rede apresentado neste trabalho foi bastante simplificado com o intuito de permitir sua simulação pela técnica de Monte Carlo [10] sem, entretanto, comprometer a capacidade de avaliar comparativamente as diferentes estratégias de dormência e atividade dos nós sensores da rede.

A rede de sensores é composta por nós sensores estáticos e idênticos, uniformemente distribuídos sobre um disco de raio unitário. Assume-se que o número de nós sensores é suficiente para garantir que a rede seja conexa (todo nó sensor possui ao menos um caminho até o nó sink) e que haja cobertura do ambiente monitorado durante o tempo operacional da rede. Todos os nós sensores são equipados com antenas omni-direcionais e o raio de transmissão é igual ao raio de interferência, ou seja, uma transmissão pode interferir em todos os outros nós sensores dentro de seu raio de alcance. O protocolo CSMA/CA [11] é utilizado e o canal sem fio é considerado isento de erros.

As informações detectadas (resultantes do sensoriamento do ambiente) são encapsuladas em unidades de dados de tamanho fixo (pacotes) e armazenadas em buffers de tamanho infinito com atendimento FIFO (First In, First Out). O tempo para transmissão dos pacotes entre dois nós sensores ou entre um nó sensor e o nó sink é unitário e denominado time-slot. As unidades de detecção e transmissão são independentes, isto é, os nós sensores podem transmitir e detectar eventos simultaneamente. Entretanto, os sensores não podem transmitir e receber pacotes no mesmo time-slot.

A evolução dos estados ativo-dormente de cada nó, é descrita em fases: uma dormente $(S)$ e uma ativa $(A)$. Os tempos nos estados dormente e ativo dos nós sensores são modelados segundo variáveis aleatórias geometricamente distribuídas, com tempos médios iguais a $1 / a$ e $1 / s$, respectivamente. Quando no estado dormente, em cada time-slot, é sorteada uma variável aleatória com probabilidade $a$ de mudar o estado do nó para ativo no próximo time-slot. E, quando no estado ativo, é sorteada com probabilidade $s$ a mudança para o estado dormente no próximo timeslot. Se o buffer do nó não estiver vazio, o nó muda para um estado intermediário denominado estado $N$. No estado ativo, o nó é capaz de realizar sensoriamento, recepção e transmissão de pacotes. No estado dormente, o nó sensor desliga o transceptor e a unidade de sensoriamento. No estado $N$, o nó sensor não recebe pacotes provenientes de outros nós e desliga a unidade de sensoriamento para passar, o mais breve possível, para a fase de dormência, porém o sensor continua a transmitir pacotes.

O consumo de energia por time-slot do nó $i$ no estado ativo é dado por

$$
c_{A}=e_{A}+c_{i j}
$$

sendo $c_{i j}$ a energia consumida na transmissão do nó $i$ para o nó $j$ e $e_{A}$ é a energia gasta para manter o nó sensor totalmente funcional. Note que a parcela $c_{i j}$ é adicionada apenas quando houver transmissão para o nó $j$ no time-slot considerado. A energia $c_{i j}$ é dada por

$$
c_{i j}=2\left(e_{T}+e_{P}\right)+e_{M} d_{i j}^{2},
$$

sendo $e_{T}$ a energia do transceptor, $e_{P}$ a energia de processamento, $e_{M}$ a energia do amplificador e $d_{i j}$ a distância entre os nós $i$ e $j$.

O consumo de energia por time-slot do nó $i$ no estado dormente é dado por

$$
c_{S}=e_{S}
$$

O consumo de energia de transição de estado dormente para ativo é dado por

$$
c_{S A}=e_{S A}
$$

e é nulo o consumo de energia de transição de estado ativo para dormente.

Com o intuito de melhorar a relação entre o consumo de energia e o atraso de transferência dos pacotes, o tempo médio de dormência de cada nó sensor é alterado em função da atividade do local sob sensoriamento. O tempo médio de dormência do nó sensor que não detectou eventos ou que não recebeu pacotes durante seu último período de atividade é aumentado, de forma a gradualmente encontrar um ciclo apropriado para o nó. Na primeira estratégia proposta, denominada recuo-exponencial e representada na Figura 1, se não houve ação do nó sensor durante a permanência no último estado ativo, o tempo médio de dormência é o dobro de seu valor nominal; e o tempo médio de dormência é mantido em seu valor nominal se houve atividade. Na segunda estratégia proposta, chamada recuo-avanço-exponencial e representada na Figura 2, se houve atividade do nó durante seu último estado ativo, o tempo médio de dormência é alterado para metade do valor corrente; e se não houve atividade, o tempo médio de dormência é o dobro do valor corrente. Os valores dos tempos médios de dormência não podem ser menores que a metade do valor nominal e nem ultrapassar o dobro desse valor.

O algoritmo de encaminhamento na rede ad hoc de sensores usa o protocolo DSR (Dynamic Source Routing) 


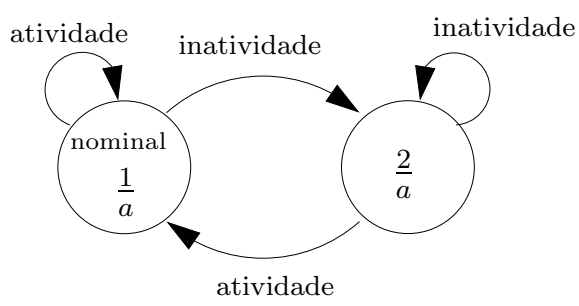

Fig. 1. Cadeia de Markov da estratégia recuo-exponencial.

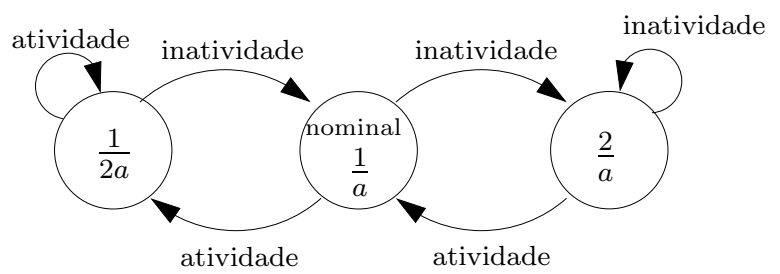

Fig. 2. Cadeia de Markov da estratégia recuo-avanço-exponencial.

[12] que na simulação de Monte Carlo é emulado pelo procedimento a seguir. Na fase de inicialização da simulação, cada sensor constrói uma tabela contendo até $M$ nós next-hops. Cada nó next-hop corresponde a uma rota de encaminhamento diferente e são escolhidos baseado no mínimo custo energético destes até o sink. A energia $c_{i j}$ de cada hop é dada pela Equação (2). O primeiro next-hop de cada nó é determinado rodando o algoritmo de Dijkstra sobre a rede considerada. Os demais nexthops são determinados da seguinte forma: elimina-se o enlace entre o nó considerado e o next-hop encontrado na última iteração e aplica-se, novamente, o algoritmo de Dijkstra sobre a rede. Um outro nó é considerado next-hop se a energia gasta para chegar até o sink for menor do que a energia gasta relativa ao nó ao qual ele está se candidatando a next-hop. Todos os nós sensores dentro do alcance do nó sink transmitem suas informações diretamente para ele. $\mathrm{O}$ menor custo energético define a prioridade de rotas na tabela de encaminhamento dos nós sensores. Quanto menor for o consumo de energia de um caminho, maior será sua prioridade.

O nó $i$ que deseja transmitir para o nó $j$ acessa o meio de transmissão se sentir o meio ocioso. De forma a emular o protocolo CSMA/CA na simulação de Monte Carlo, considera-se que todos os nós no raio de alcance $r$ (raio de transmissão) do nó $i$ são bloqueados, reservando o meio para a transmissão do nó $i$. Todos os nós no raio de alcance do nó $j$ são também bloqueados, emulando a escuta do pacote CTS (clear to send) enviado pelo nó $j$ em resposta ao pacote RTS (request to send) recebido do nó $i$. Em cada time-slot o sensor $i$ é escolhido aleatoriamente dentre todos aqueles que têm pacotes para transmitir e o sensor $j$ é escolhido como aquele de menor gasto energético dentre todos os next-hops ativos de $i$, permitindo, assim, a transmissão simultânea dos pares que não colidem entre si.

\section{A. Algoritmo de Simulação de Monte Carlo Inicialização}

1) Distribua uniformemente $\nu$ nós sensores sobre um disco de raio unitário.

2) Posicione o nó sink no centro do disco.

3) Determine para todos os nós sensores até $M$ caminhos mínimos, com os menores custos energéticos, até o sink.

- Primeiro, determine os caminhos mínimos de todos os nós sensores até o sink.

- Um novo caminho para o nó $i$ é escolhido se o custo energético associado ao último nó, $j$, da nova rota for menor do que o custo de $i$.

- Utiliza-se o algoritmo de Dijkstra para encontrar os caminhos mínimos.

4) Sorteie aleatoriamente $\lceil\nu s /(s+a)\rceil$ nós e os coloque no estado dormente, lista_S.

5) lista_ $R$ será composta pelos nós que não fazem parte da lista_S.

6) Defina lista $n B$ com os nós que não estão bloqueados para receber, isto é, os nós da lista_R e o nó sink, e lista_N, com os nós no estado $N$.

\section{Loop}

1) Sorteie aleatoriamente da lista_R com probabilidade $g$, dada por

$$
g=\frac{s+a}{a} \frac{G}{\nu}
$$

sendo $G$ a carga da rede, os nós que geram pacotes e adicione um pacote em seus buffers.

2) Crie lista_F com os nós da lista_R e da lista $\_N$ que possuem pacotes a transmitir.

3) A lista_nB conterá os nós que podem receber pacotes, isto é, os nós da lista_R e o sink.

4) Enquanto $l i s t a \_n B$ ou lista $\_F$ não forem vazias

a) Sorteie um nó transmissor da lista_F e busque seu next-hop, com menor custo energético, na lista_nB.

b) Se não houver um receptor para esse transmissor, retire o nó transmissor da lista_F e retorne para 4a.

c) Se houver um nó receptor, retire da lista $n B$ todos os nós no raio de alcance, $r$, do transmissor e retire da lista_F todos os nós no raio de alcance, $r$, do receptor.

d) Acrescente um pacote no buffer do receptor e retire um pacote do buffer do transmissor.

e) Retire o transmissor e o receptor da lista_nB e da $l i s t a \_F$ e retorne para $\mathbf{4 a}$.

5) Os nós sensores da lista_N sem pacotes em seus buffers passam para a lista_S.

6) Os nós sensores na lista_R passam para a lista_N, com probabilidade $s$, se houver pacotes em seus buffers e para a lista_S caso contrário.

7) Os nós sensores na lista_S passam para a lista_R com probabilidade $a$.

- Na estratégia recuo-exponencial: Se não houve ação do nó sensor durante o último time-slot, o tempo médio de dormência é o dobro de seu 
valor nominal; caso contrário o valor nominal é mantido.

- Na estratégia recuo-avanço-exponencial: o valor do tempo de dormência é metade do valor anterior se houve atividade no último time-slot, senão o tempo médio é o dobro do valor anterior, não ultrapassando duas vezes o valor nominal.

8) Repita Loop até que, pelo menos, um certo número de pacotes de cada nó sensor tenha sido entregue ao nó sink.

\section{EXPERIMENTOS NumÉRICOS}

O desempenho das duas estratégias propostas, redução do consumo de energia por recuo-exponencial e por recuoavanço-exponencial, foi avaliado via simulação de Monte Carlo e os resultados foram comparados com aqueles publicados em [9]. O atraso médio de transferência de pacotes e a energia média consumida por nó sensor em função do período de dormência dos nós e em função da taxa de transição entre estados foram analisados.

A Tabela I apresenta os principais parâmetros utilizados na simulação obtidos em [9].

TABELA I

ParÂmetros da simulação de Monte Carlo.

\begin{tabular}{l|c}
\hline Número de nós sensores & $\nu=400$ \\
Raio de transmissão & $r=0.25$ \\
Área sob sensoriamento & disco de raio unitário \\
\hline Consumo de energia por time-slot & \\
- do amplificador & $e_{M}=0.0570 \mathrm{~mJ}$ \\
- do transceptor & $e_{T}=0.2400 \mathrm{~mJ}$ \\
- do processamento & $e_{P}=0.2400 \mathrm{~mJ}$ \\
- do estado dormente & $e_{S}=0.0003 \mathrm{~mJ}$ \\
- do estado ativo & $e_{A}=0.2400 \mathrm{~mJ}$ \\
\hline Transição de dormente para ativo & $e_{S A}=0.4800 \mathrm{~mJ}$ \\
\hline Carga da rede & $G=0.4$ \\
Número de next-hops & até 6 \\
\hline
\end{tabular}

Os atrasos médios de transferência de pacotes expressos em time-slots em função do tempo médio de dormência $(1 / a)$ para um tempo médio ativo igual a $1 / s=10$ são mostrados na Figura 3 . Note que para $1 / a<1 / s$ os atrasos médios de transferência são praticamente idênticos. Cabe ressaltar que o atraso na transferência de pacotes é diretamente influenciado pelo número de sensores dormentes, quanto maior a quantidade e quanto mais tempo os sensores permanecerem em tal estado, maior será o atraso. As energias médias consumidas por sensor por time-slot em função do tempo médio de dormência $(1 / a)$ para $1 / s=10$ são mostradas na Figura 4 . Note a significativa redução do consumo de energia das propostas apresentadas quando comparada com a estratégia de Chiasserini e Garetto. Os produtos dos atrasos médios de transferência pelos consumos médios energéticos por nó sensor por time-slot são mostrados na Figura 5. Observe que, em primeira aproximação, são melhores as estratégias que têm os menores produtos. A curva da estratégia recuo-avanço-exponencial indica um melhor desempenho quando o atraso e o consumo de energia são avaliados

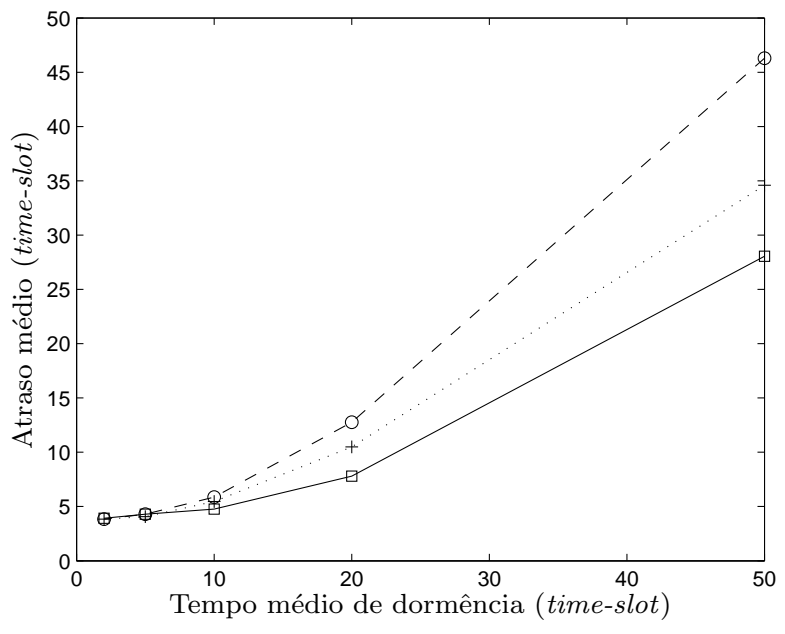

Fig. 3. Atraso médio de transferência de pacotes em função do tempo médio de dormência $1 / a$ para $1 / s=10$. Estratégia publicada em [9](curva contínua); Recuo-exponencial (curva tracejada); e Recuoavanço-exponencial (curva pontilhada).

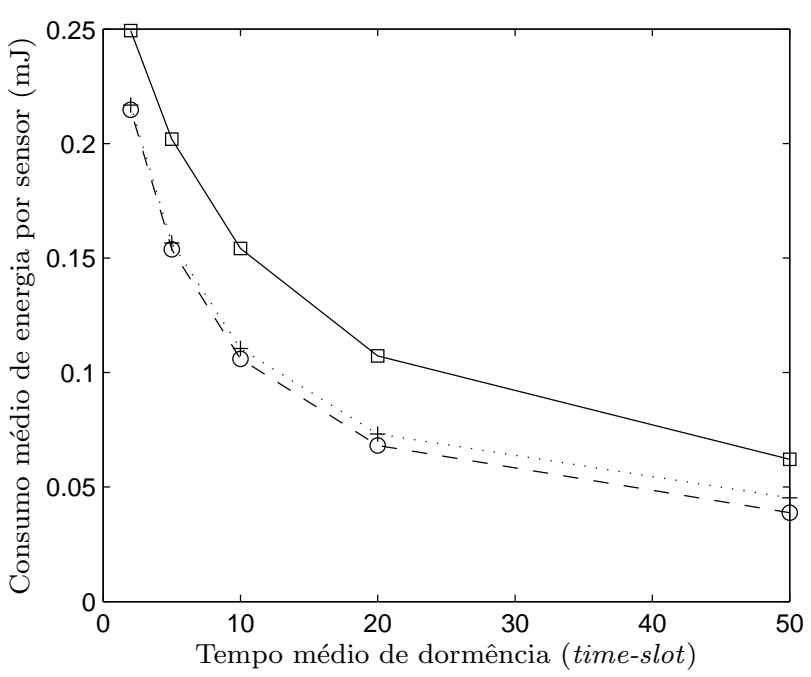

Fig. 4. Consumo médio de energia por sensor por time-slot em função do tempo médio de dormência $1 / a$ para $1 / s=10$. Estratégia publicada em [9](curva contínua); Recuo-exponencial (curva tracejada); e Recuo-avanço-exponencial (curva pontilhada).

conjuntamente e indicam, também, que os parâmetros $s$ e $a$ devem ser fixados em 0.1 nas condições simuladas.

Se os tempos médios de dormência e de atividade forem idênticos cada nó fica metade do tempo dormente e metade ativo. Entretanto, a freqüência de transição entre os estados ativo e dormente é tanto maior quanto menor forem esses tempos médios. Para avaliar a melhor escolha desses tempos novas simulações foram realizadas com $1 / s=1 / a$ e os resultados são mostrados na figuras 6 e 7 . O aumento considerável no consumo de energia, sem diminuição significativa nos tempos de atraso, para tempos médios inferiores a 10 time-slots indica que a solução apropriada para os tempos médios para a rede nas condições simuladas é igual a 10. 


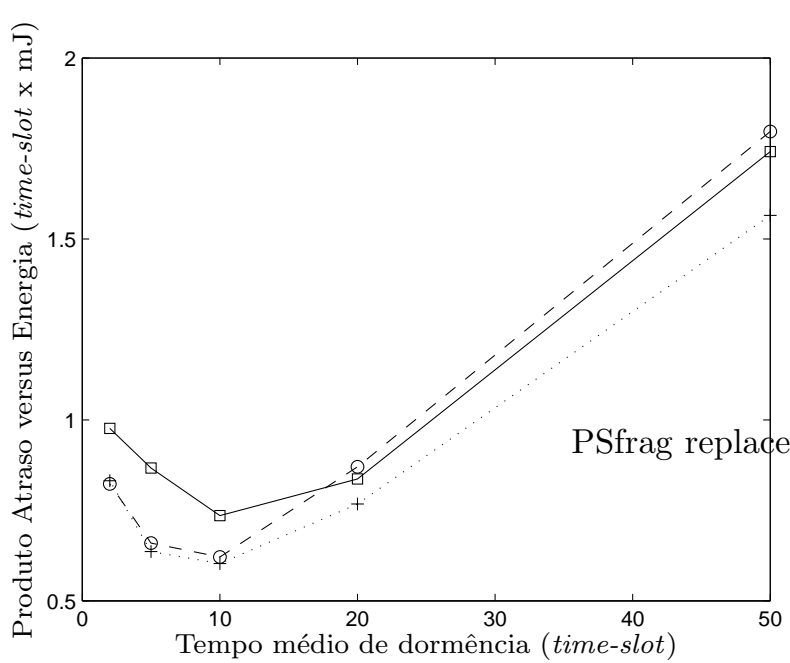

Fig. 5. Produto atraso versus consumo de energia em função do tempo médio de dormência $1 / a$ para $1 / s=10$. Estratégia publicada em [9](curva contínua); Recuo-exponencial (curva tracejada); e Recuo-avanço-exponencial (curva pontilhada).

A Figura 8 mostra os produtos dos atrasos médios de transferência pelos consumos médios energéticos por nó sensor por time-slot para o caso de $1 / a=1 / s$. Novamente, a curva da estratégia recuo-avanço-exponencial indicou um melhor desempenho quando avalia-se, conjuntamente, o atraso e a energia gasta.

A análise dos valores apropriados para os parâmetros $a$ e $s$ só pode ser realmente feita através de um modelo analítico que permita o estudo detalhado do desempenho da rede em função desses parâmetros. Os autores pretendem generalizar o modelo analítico apresentado em [9] e validá-lo pelo modelo de simulação de Monte Carlo.

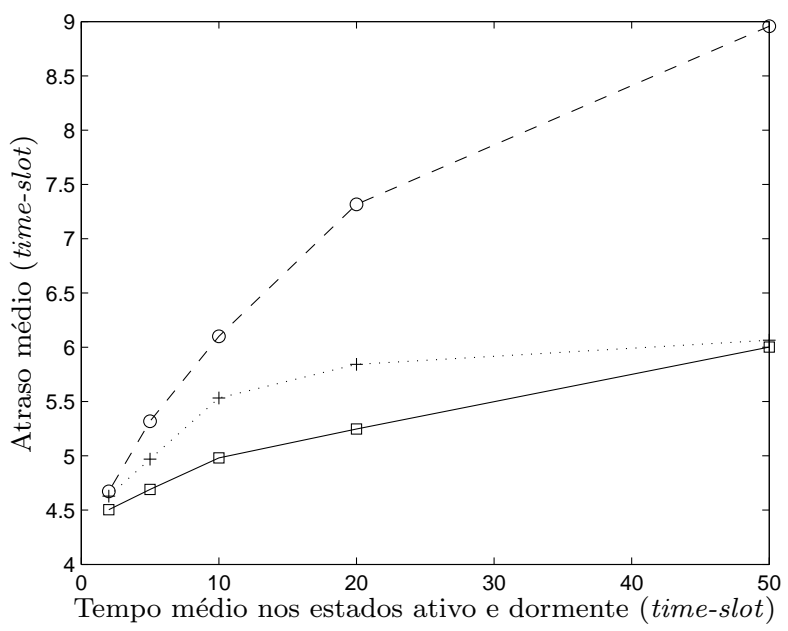

Fig. 6. Atraso médio de transferência em função dos tempos médios nos estados ativo e dormente $(1 / a=1 / s)$. Estratégia publicada em [9](curva contínua); Recuo-exponencial (curva tracejada); e Recuoavanço-exponencial (curva pontilhada).

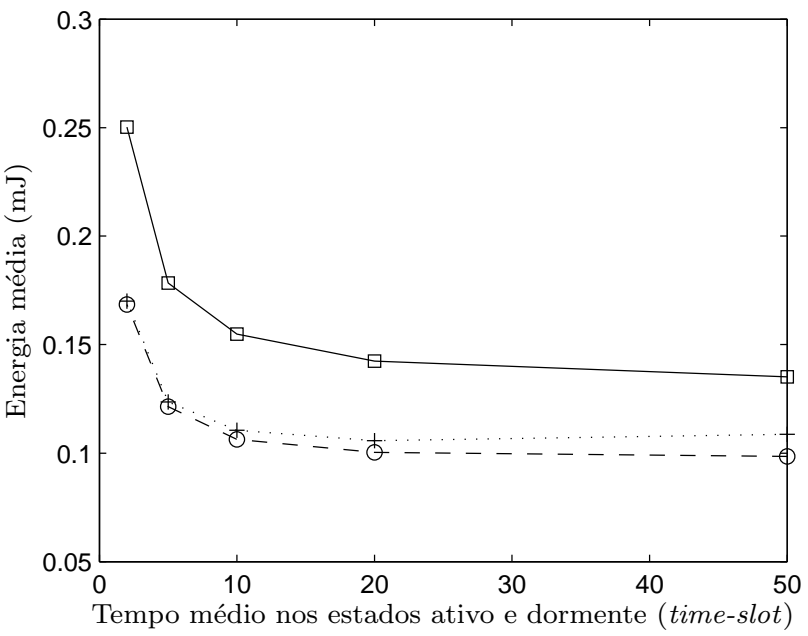

Fig. 7. Energia média consumida por nó sensor por time-slot em função dos tempos médios nos estados ativo e dormente $(1 / a=1 / s)$. Estratégia publicada em [9](curva contínua); Recuo-exponencial (curva tracejada); e Recuo-avanço-exponencial (curva pontilhada).

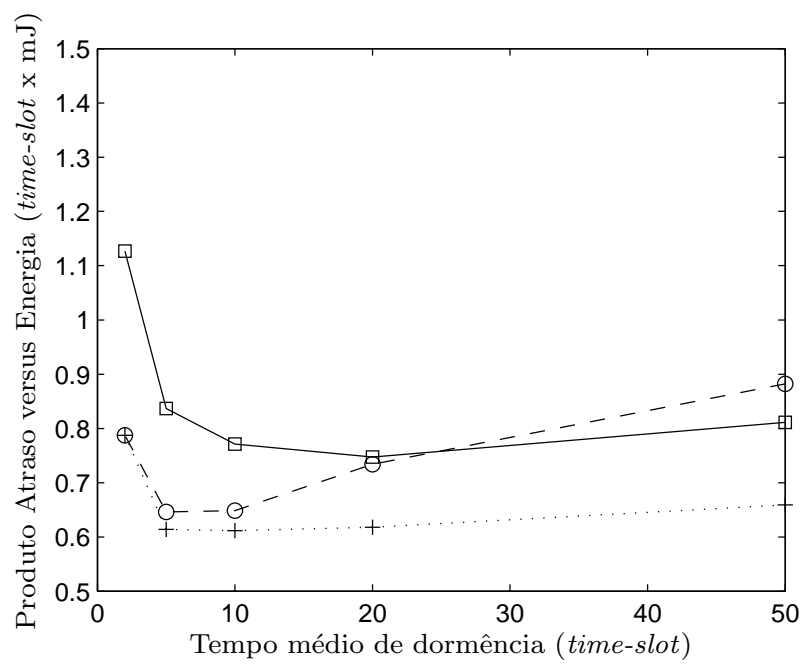

Fig. 8. Produto atraso versus consumo de energia em função do tempo médio nos estados ativo-dormente com $1 / a=1 / s$. Estratégia publicada em [9](curva contínua); Recuo-exponencial (curva tracejada); e Recuo-avanço-exponencial (curva pontilhada).

\section{CONCLUSÃO}

Duas novas estratégias de redução do consumo energético para redes de sensores sem fio, denominadas recuo-exponencial e recuo-avanço-exponencial, foram propostas neste trabalho. As estratégias são baseadas na alteração do tempo de dormência dos nós sensores em função da freqüência de detecção de eventos no ambiente alvo de sensoriamento e do nível de atividade dos nós quando encaminhando os dados coletados por outros nós da rede.

Os resultados das simulações mostram que tanto a estratégia recuo-exponencial quanto a estratégia recuoavanço-exponencial apresentaram uma redução do consumo energético, mas aumentaram o atraso na transferência de pacotes. Dentre ambas, a estratégia de recuo- 
avanço-exponencial apresentou o menor produto atraso vezes energia despendida, mostrando que, apesar do aumento do atraso na transferência, a energia economizada proporciou um maior tempo de vida para toda a rede.

\section{Agradecimentos}

Este trabalho foi apoiado pelos Conselho Nacional de Desenvolvimento Científico e Tecnológico - CNPq, Coordenação de Aperfeiçoamento de Pessoal de Nível Superior - CAPES, Fundação de Amparo à Pesquisa do Estado de São Paulo - FAPESP e Instituto Nacional de Telecomunicações - INATEL.

\section{REFERÊNCIAS}

[1] I. F. Akyildiz, W. Su, Y. Sankarasubramaniam, and E. Cayirci. Wireless sensor networks: a survey. Computer Networks, 38(4):393 - 422, December 2002.

[2] Mohammad Ilyas and Imad Mahgoub. Handbook of sensor networks: Compact wireless and wired sensing systems. CRC Press LLC, 2005.

[3] K. Kredo II and P. Mohapatra. Medium access control in wireless sensor networks. Computer Networks, 51(4):961994, 2007.

[4] C. Hsin and M. Liu. Network coverage using low dutycycled sensors: random \& coordinated sleep algorithms. In IPSN '04: Proceedings of the third international symposium on Information processing in sensor networks, pages 433442, New York, NY, USA, 2004.

[5] W. Ye, J. Heidemann, and D. Estrin. Medium access control with coordinated adaptive sleeping for wireless sensor networks. IEEE/ACM Transactions Networking, 12(3):493-506, June 2004.

[6] T. V. Dam and K. Langendoen. An adaptive energyefficient MAC protocol for wireless sensor networks. In Proceedings of the First international conference on Embedded networked sensor systems, pages 171-180, New York,USA, 2003.

[7] P. Lin, C. Qiao, and X. Wang. Medium access control with a dynamic duty cycle for sensor networks. In Proceedings of the IEEE Wireless Communications and Networking Conference, volume 3, pages 1534-1539, March 2004.

[8] S. Singh and C. S. Raghavendra. Pamas - power aware multi-access protocol with signalling for ad hoc networks. SIGCOMM Comput. Commun. Rev., 28(3):5-26, 1998.

[9] C. F. Chiasserini and M. Garetto. An analytical model for wireless sensor networks with sleeping nodes. Mobile Computing, IEEE Transactions on, 5:1706 - 1718, December 2006.

[10] David Vose. Quantitative Risk Analysis: A Guide to Monte Carlo Simulation Modelling. John Wiley and Sons Ltd., 1996.

[11] G. Bianchi. IEEE 802.11 - saturation throughput analysis. IEEE Communications Letters, 2(12):318-320, December 1998.

[12] D. B. Johnson and D. A. Maltz. Dynamic source routing in ad hoc wireless networks. In Imielinski and Korth, editors, Mobile Computing, volume 353, chapter 5, pages 153-181. Kluwer Academic Publishers, 1996. 